\title{
Measuring Food and Nutrition Security: Tools and Considerations for Use Among People Living with HIV
}

\author{
Sarah J. Fielden · Aranka Anema · Pamela Fergusson • \\ Katherine Muldoon $\cdot$ Nils Grede $\cdot$ Saskia de Pee
}

Published online: 3 December 2013

(c) Springer Science+Business Media New York 2013

\begin{abstract}
As an increasing number of countries implement integrated food and nutrition security (FNS) and HIV programs, global stakeholders need clarity on how to best measure FNS at the individual and household level. This paper reviews prominent FNS measurement tools, and describes considerations for interpretation in the context of HIV. There exist a range of FNS measurement tools and many have been adapted for use in HIV-endemic settings. Considerations in selecting appropriate tools include subtypes (food sufficiency, dietary diversity and food safety); scope/level of application; and available resources. Tools need to reflect both the needs of PLHIV and affected households and FNS program objectives. Generalized food sufficiency and dietary diversity tools may provide adequate measures of FNS in PLHIV for programmatic applications. Food consumption measurement tools provide further data for clinical or research applications. Measurement of food safety is an important, but underdeveloped aspect of assessment, especially for PLHIV.
\end{abstract}

\section{S. J. Fielden $(\bowtie) \cdot$ K. Muldoon}

School of Population and Public Health, University of British

Columbia, 2206 East Mall, UBC Point Grey Campus,

Vancouver, BC V6T1Z3, Canada

e-mail: sjfielden@yahoo.ca; s.fielden@alumni.ubc.ca

\author{
A. Anema \\ British Columbia Centre for Excellence in HIV/AIDS, St. Paul's \\ Hospital, 608-1081, Burrard St, Vancouver, BC V6Z1Y6, \\ Canada \\ P. Fergusson \\ Centre for International Health and Development, Institute of \\ Child Health, University College London, London, UK \\ N. Grede $\cdot$ S. de Pee \\ HIV/AIDS and Nutrition, World Food Program, Rome, Italy
}

Keywords Food and nutrition security · HIV . Measurement · Food consumption · Dietary diversity, food safety

\section{Introduction}

While the bi-directional linkages between food and nutrition security (FNS) and HIV/AIDS are widely acknowledged [1, 2], the integration of FNS into HIV interventions at clinical and programmatic levels still lacks harmonized definitions and indicators [3]. Global stakeholders are working to standardize FNS program monitoring and evaluation indicators for HIV to inform program design and implementation for people living with HIV (PLHIV) and in HIV-endemic settings. Developing these and standardizing their use across bilateral and multilateral organizations offers opportunities for better assessing population needs, for improving the tracking of programmatic outcomes and ultimately for informing evidencebased policies and programs which effectively integrate FNS and HIV [4]. Even when program managers and policy-makers adopt these harmonized definitions and population-level indicators for their high-level reporting, there will also be a need to ensure that program managers, clinicians and researchers are measuring FNS in a way that both contribute to these higher level indicators, while also providing information relevant for their programmatic and clinical decision-making. The choice of tool to assess FNS in PLHIV as well as those affected varies as a function of why the information is gathered: research; programmatic needs assessment, program design, monitoring and evaluation; or individual clinical management. The potential range of interventions and responses also impact on the choice of tool as does whether or not the main objective is 
improving or stabilizing individual or household food security, improving adherence to treatment or retention in care, or improving nutritional status.

This paper therefore reviews prominent FNS and food consumption measurement instruments that can be used to assess individual and household-level food and nutrition insecurity. We describe tools that may be used to measure general food insecurity, highlighting instruments that have been used and validated in HIV-endemic settings. We review FNS measures that can be helpful for understanding subcomponents (i.e. sufficiency, quality and safety) of food insecurity, dividing them into unidimensional and multidimensional categories [4]. Throughout the paper we describe practical and theoretical considerations that stakeholders must consider when estimating food insecurity at individual and household levels, including effects of HIV illness, antiretroviral therapy (ART) use, the global emergence of 'overnutrition', and the unique vulnerabilities of certain populations.

\section{Background and Key Considerations for Measurement}

What makes HIV unique in terms of its impact on FNS is the number of factors that intersect. These factors include the physiological as well as the economic, socio-cultural and/or psychosocial. Researchers, program designers and policymakers need to understand how HIV affects these factors at the individual and household levels. At the individual level, food, nutrition and HIV are closely physiologically interrelated [5-8]. Macronutrient, micronutrient and energy deficiencies are well-documented complications of HIV infection both before and during highly active antiretroviral therapy (HAART). Common manifestations of these deficiencies include anemia, other micronutrient deficiencies and HIV-associated wasting. Deficiencies in vitamin A, B12, selenium and zinc have been reported and are associated with progression of HIV infection [9-11]. HIV infection is a chronic inflammatory state that has been found to increase energy needs above normal requirements [12, 13]. Foodborne illnesses may also contribute to malnutrition in PLHIV given their increased susceptibility to these types of infections. PLHIV often experience severe diarrhea and fever, thereby increasing nutrient losses as well as nutrient needs [14]. Poor nutritional status can impact on immune function and mortality rates are higher among malnourished PLHIV, including those on HAART [8].

HIV-related complications of HAART such as fat redistribution syndrome (lipodystrophy) and unbalanced diets (with overconsumption of some food types, often high in sugar and fat, and underconsumption of others rich in protein, macrominerals and micronutrients such as meat, fish, dairy, fruits and vegetables) may make it difficult to detect malnutrition by just using anthropometric measurements such as body mass index (BMI) or mid-upper arm circumference (MUAC) [15], the simple tools available and commonly used in low income contexts. As an ever larger percentage of the general population is overweight or obese in many low income settings [16], it may be harder to link such conditions to HIV. In many cases, HIV may make the consequences of poor dietary intake worse with the difference between an HIV positive and an HIV negative person being the extent to which they suffer from malnutrition-related challenges. This may mean that actual malnutrition rates due to HIV may often be underestimated among PLHIV.

Nevertheless, HAART has had some positive impacts on nutritional status in the context of HIV, and has been associated with improvements in BMI, growth, and nutrient status [17-20]. However, a lot of the literature has focused on undernourished PLHIV graduating from undernutrition while not being sensitive to often significant increases in the percentage of overweight patients. Finally, HIV infection is a chronic and life-long condition and its impact on FNS at the individual level may be far reaching. Evidence shows that PLHIV may face a higher risk of chronic diseases such as diabetes and cardio-vascular disease [20,21], conditions which also require careful nutritional management. Food insecurity and elderly PLHIV is also emerging as an important issue [22, 23].

While there is much focus in the literature on the HIVinfected individual, individuals live in households which care for them and to whose income they contribute. They share income and expenditures, and there is ample evidence how disease can increase household expenditures while often simultaneously reducing its income, especially when the infected person is the breadwinner. The risk of engaging in irreversible negative coping behaviours to mitigate the impact of HIV on them is widely documented [24]. HIV may also reduce household income due to illness or death and resources may be diverted to pay for treatment-related or funeral expenses. Affordability determines economic access, which is a critical component of household FNS in addition to availability as well as utilization. Household food access can be described as the "ability to acquire sufficient quality and quantity of food to meet all members' nutritional requirements for productive lives" [25].

Dietary sufficiency and dietary diversity can be measured at both the individual and household level. While household members share meals, we often insufficiently understand how intra-household distribution works and affects individuals. Measuring them at both levels can help shed light, especially if we have reason to believe that PLHIV may be discriminated against for any potential 
reason (gender, age, HIV-related stigma etc.). As meals are shared, food safety is the same for all household members, but when food safety issues are present, they may affect the vulnerable household members more negatively. This would include the PLHIV, but also people who are sick, young children, the elderly or pregnant and lactating women.

Finally there are cultural factors which affect individuals and households alike. PLHIV and their close contacts are often impacted by multiple layers of stigma [26, 27], rarely seen with other medical conditions [28-30]. The stigma of having HIV may be exacerbated by discrimination directed towards key populations such as men who have sex with men (MSMs), illicit drug users, and sex workers. Like other PLHIV, these groups may face competing demands for resources [31, 32], limiting their access to food and, therefore, the quality and quantity of food they consume. Also, stigma may cause them to start treatment much later than their peers, when their health and nutritional status are likely to have deteriorated significantly.

\section{Food and Nutrition Scurity Measures}

The range of tools used to measure FNS is broad, and previous publications have reviewed the evolution of select FNS measures and compared and contrasted their utility in a wide range of settings and populations [33-35]. Numerous survey scales and metrics have been developed to measure FNS and are extensively used internationally with many populations including PLHIV. Some of these have also been used and validated in HIV-endemic settings, offering opportunity for expanded use and for cross-cultural comparisons. Table 1 provides a summary of commonly applied FNS measurement tools that have been validated in one or more HIV-endemic countries, as well as in other settings. Validation in these settings is important as it allows for more confidence in the utility of the tools in different countries and populations. Although validated in HIV-endemic countries, there is limited evidence of these tools being applied among populations of PLHIV more explicitly. Among the tools listed in Table 1 for example, we were unable to locate any publications where the Women's Dietary Diversity Scale (WDDS) was used among PLHIV specifically.

Many multilateral and bilateral organizations such as the World Food Programme (WFP), International Food Policy Research Institute (IFPRI), and the Food and Nutrition Technical Assistance program (FANTA) have taken the lead in developing and adapting metrics for use in lowresource settings, for example the Household Dietary Diversity Score (HDDS), Months of Adequate Household Food Provisioning (MAHFP), the Food Consumption
Score for measurement of household food access [25, 36, 37]. They are widely used by the United Nations WFP, but less typically with PLHIV.

One of the earliest tools to measure FNS is the RadimerCornell scale which was used as the basis for many of the subsequent tools including the most widely used and adapted food security scale from the USDA's Household Food Security Survey Module (HFSSM) and the Household Food Insecurity Access Scale (HFIAS) [38] and adapted Canadian versions of the module [39], offering some degree of geographic and temporal comparability. More recently, FANTA has developed a cross-culturally validated Household Hunger Scale (HHS) [40]. These generalized FNS measurement tools include questions such as "In the past 4 weeks, did you or any household member have to eat fewer meals in a day because there was not enough food?" (sample question taken from the HFIAS [41]). Over the years, many international HIV cohort studies have applied these tools. For example, several HIV cohorts in the US and Canada have relied on modified versions of the Radimer-Cornell scale [42-46]. The HFIAS has been used in several HIV cohorts in the US [47, 48], and among HIV-positive populations in Zambia, Uganda and Kenya [49-51]. The Household Food Security Scale-Short Form (HFSS-SF) was recently applied in cohorts of PLHIV in Tanzania [52] and Vietnam [53].

Food and nutrition insecurity measurement tools can be understood as those that measure general food insecurity such as the surveys described above and/or its three subcomponents of food insufficiency, poor dietary diversity, and poor food safety. For a detailed description of these terms and their implications, see Anema et al. [4]. Briefly, food insufficiency describes a lack of adequate caloric intake to meet energy requirements; poor dietary diversity implies a lack of dietary quality and inability to meet nutrient requirements (i.e. inadequate amounts of individual macro and micro-nutrients); and poor food safety represents an increased risk of foodborne illness due to contamination.

Measurement of these three sub-types of food and nutrition insecurity in HIV-positive populations may include: surveys of food insecurity components, and dietary intake assessment. Dietary sufficiency and diversity can be measured using survey tools that typically ask for type, amounts and/or frequency of consumption of various foods and food groups based on recalls. Dietary quantity and quality is then derived and interpreted from the data, based on the assumption that greater dietary sufficiency represents greater dietary quantity and that dietary diversity represents greater dietary quality (nutrient needs are better met). Food groups such as meat, fish, dairy, fortified foods, vegetables and fruits contribute many essential macro and micronutrients. Food safety can be measured using direct 


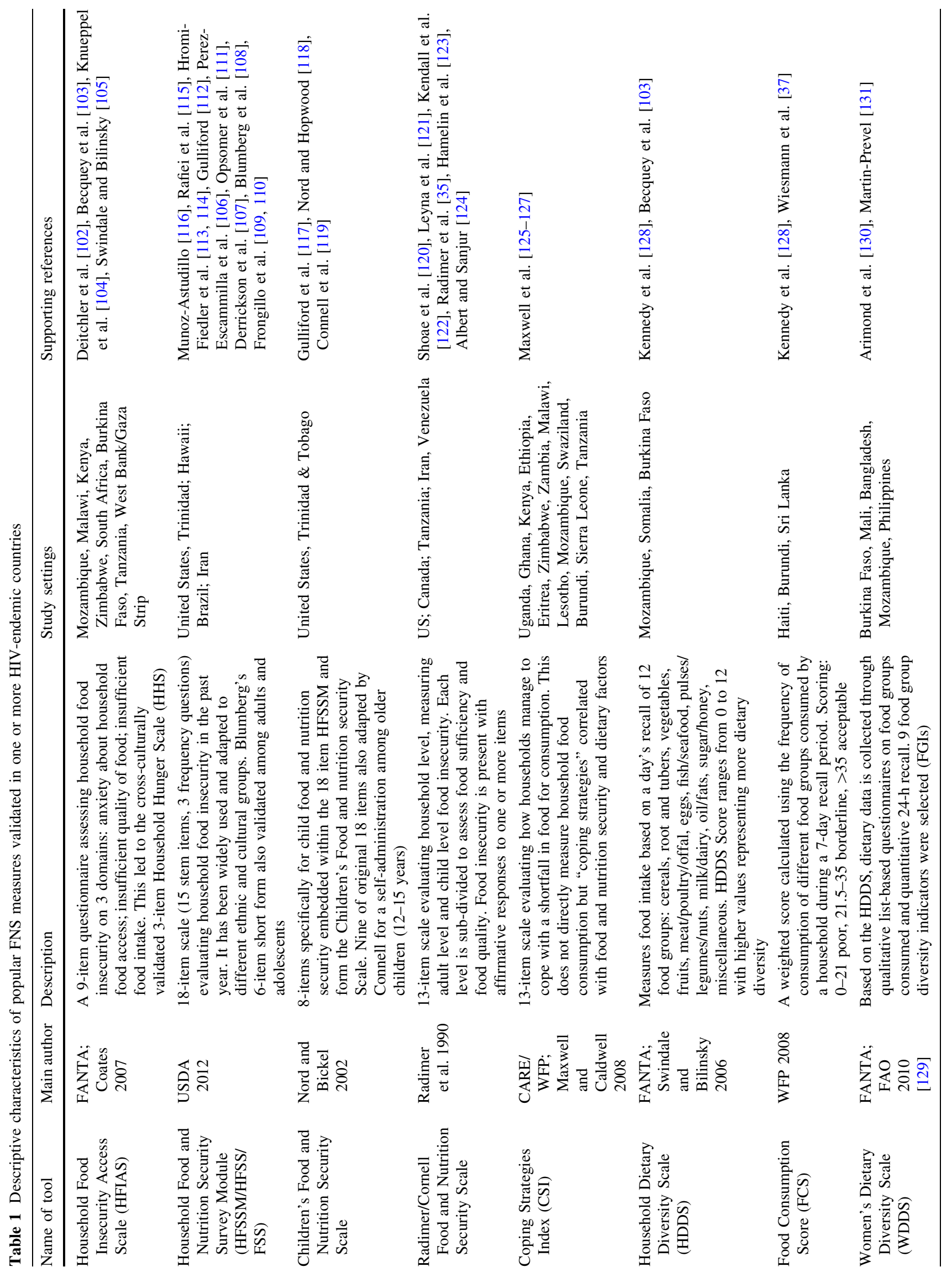


measures of foodborne pathogens or indirect measures such as self-report surveys related to cooking, hygiene, and sanitation practices.

While access to a nutritionally adequate diet is one enabler of a healthy nutritional status, availability and utilization are also important to consider. In some contexts, nutritious food may not be available due to the lack of functioning markets. At times, it may not be available for part of the year, typically during the lean season. Other times, it is available, but at unaffordable prices, which then translates into an access problem. More importantly, HIV affects the metabolism. Those infected do not only need more energy and proportionally more of different nutrients, but at times also suffer from a reduced ability to consume food (lack of appetite, mouth sores etc.) and digest it (nutrient absorption is reduced, and losses increased, for example due to diarrhea) [1]. Malnutrition or undernutrition as measured by nutritional screens and/or anthropometric measurements is often the result of both an inadequate access to food as well as poor utilization by the body. HIV, especially when symptomatic, prevents the body from making optimal use of the nutrients. Therefore, a low BMI, a low MUAC or micronutrient deficiencies are very common among PLHIV. WFP has assessed the nutritional status of adult PLHIV, usually in the early phase of treatment, using BMI in a number of contexts. The results show a range of between 12 and $58 \%$ undernourished, when using the definition of a BMI below 18.5. ${ }^{1}$ These results are usually caused by a combination of poor food access and utilization. In the following section we will focus on measuring different components of food and nutrition insecurity as the possible causes of poor nutritional outcomes, while anthropometric measurements are covered elsewhere [54].

Different FNS measurement tools can be classified into those which look at a single dimension (either caloric sufficiency, dietary diversity or food safety) and those that combine two or more aspects. Unidimensional tools can be simpler to implement given their brevity and offer actionable information regarding individual and household needs. However, they do not typically provide holistic understanding of food and nutrition insecurity, which by definition includes multiple dimensions. Table 2 provides a general overview of advantages and disadvantages of many of these commonly used tools.

\footnotetext{
${ }^{1}$ Data unpublished. Most assessments looked at patients in the first year after starting ART. Swaziland had the lowest rate of undernutrition with $12 \%$. Nambibia had $17 \%$, Mozambique $25 \%$, Burundi $26 \%$. Somalia (includes ART and DOTS patients) and Djibouti had the highest rates with $44 \%$ in Somalia (includes ART and DOTS patients) and $38 \%$ (ART patients) and $58 \%$ (coinfected patients) in Djibouti.
}

Tools measuring food sufficiency, diversity, and safety can provide the information that an individual or household is food insecure; however, in isolation these tools may not provide enough contextual information to guide a comprehensive intervention to improve FNS. Often it is important to use additional sources such as qualitative research to understand the causes for the FNS situation. Is it caused by an agricultural crisis? Is it due to poverty, addictions or conflict? Is it caused by illness? Is it a food access or food utilization issue? This is particularly important for PLHIV whose consumption may be reduced, not because of poor access to food, but because of feeling nauseous, lack of appetite or suffering from frequent bouts of diarrhea. Additional, often qualitative, information can be useful in better understanding the causes of food and nutrition insecurity, which is a prerequisite for many policy and program decisions for addressing them.

\section{Unidimensional Measures}

\section{Food Insufficiency Measures}

Food insufficiency is often measured using single or combined items from survey scales. A commonly accepted valid single-item measurement of food insufficiency used in epidemiological studies is the response "not enough to eat" to the question "which of the following describes the amount of food your household has to eatenough to eat, sometimes not enough to eat or often not enough to eat?" $[55,56]$. Alternatively, individual-level measures of sufficiency can use dietary intake measures with calculations of energy intake and expenditure; the latter using techniques such as the Harris Benedict Equation with a 1.3 stress factor for HIV/AIDS [13] or based on the Centers for Disease Control and Prevention (CDC) clinical staging with Category A (30-35 kcals/kg), category B (35-40 kcals/kg), and category C (40-50 kcals/kg) $[57,58]$.

The value of these food insufficiency survey scales is that they provide an efficient and inexpensive measure of FNS at the individual and/or household levels, helping to facilitate rapid programmatic needs assessment. However, they do not provide direct measures of food consumption and/or diet quality. Diet quality is also important for PLHIV who have increased nutritional requirements. A diet which is adequate in kcal to maintain a normal or even overweight BMI may mask inadequate intake of some macro and micronutrients. These diets may imply excessive consumption of certain nutrients such as fat and carbohydrates, but inadequate in others such as micronutrients and essential amino acids and fatty acids. An increasing concern is the issue of "hidden hunger" [59], 


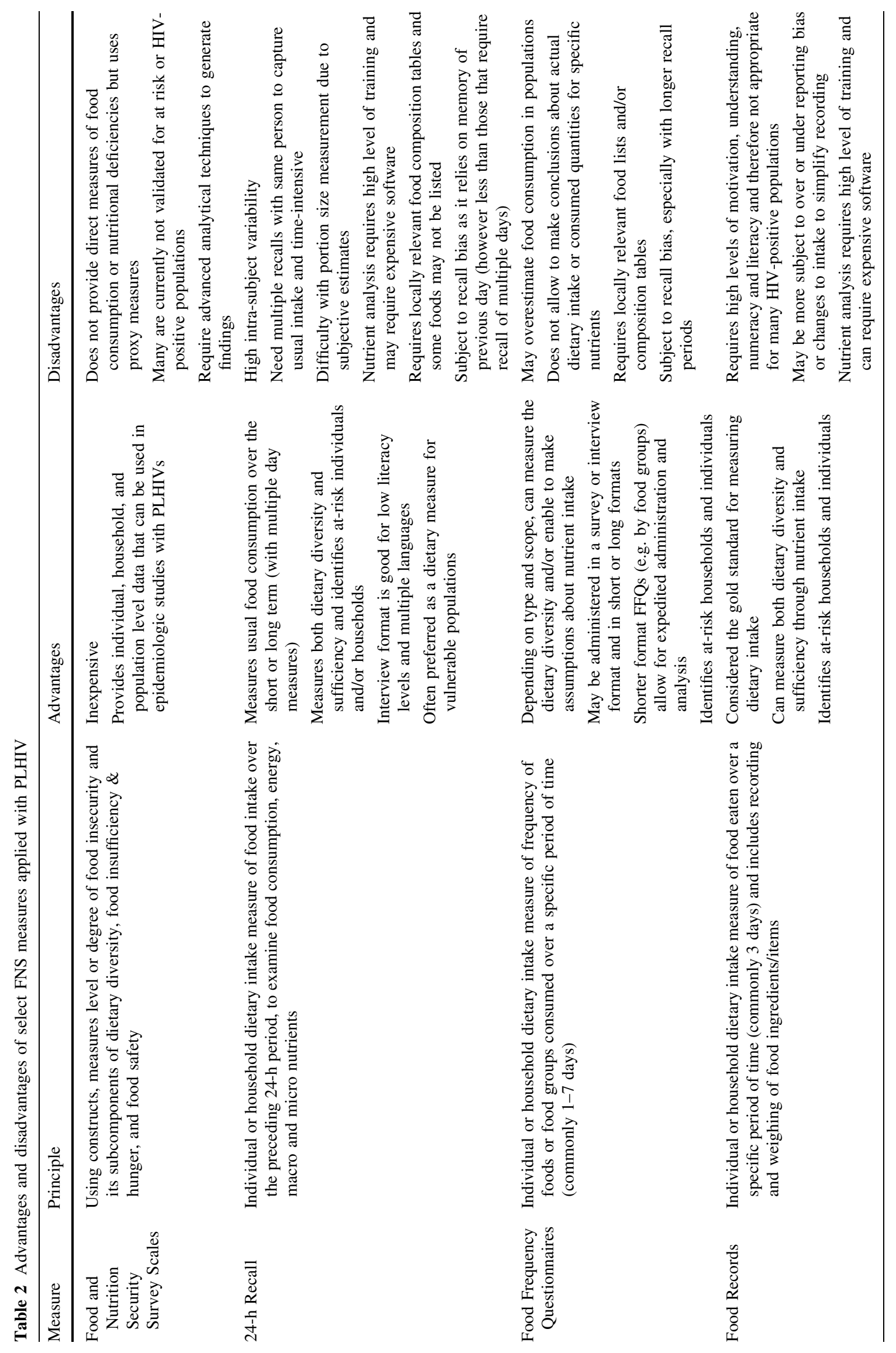


or micronutrient deficiencies. In a study of Brazilian PLHIV on HAART, being overweight was associated with poorer diet quality [60]. This double burden of malnutrition and overweight/obesity is an emerging problem for PLHIV, particularly in middle income countries. In South Africa, a 2013 study reported that stunting in children and adolescent obesity co-exist in an HIV-endemic population [61]. A study using data from 40 countries in Sub-Saharan Africa showed that populations with high levels of stunting and infant mortality also have high rates of maternal obesity [16]. This finding is not surprising as stunting is a major cause of child mortality [62], while stunted children are also more likely to face obesity later in life [63].

Diet quality and safety may be particularly compromised for some key populations such as PLHIV who use drugs. Given the competing demands on limited resources, drug users often have to trade off drug use, diet quality and diet sufficiency. This often results in the consumption of large quantities of inexpensive high-fat and high-sugar foods which fill the stomach, but do not provide the required nutrients for a healthy and active life. Much less do they meet the increased nutrient needs of a PLHIV. The same phenomenon may occur with other PLHIV living in poverty, but its incidence may be higher among drug users [64]. This information on dietary quality would not be captured using a food insufficiency scale, nor would food safety issues be identified. Neglecting to measure dietary quality and/or safety may lead to underestimate food and nutrition insecurity.

Another limitation is that some of these measures have not been validated cross-culturally, including in HIVendemic populations. Also, there is an insufficient emphasis on the importance to collect data for both infected individuals and all household members. For example in the HFSSM, where only household-level data is collected, no emphasis is placed on assessing the food insufficiency of children in a household even though household resources may need to be diverted to protect the food intake of children. There may be large variations in intra-household food allocation. For example, in some cultures the breadwinner's food intake is protected first to ensure continued household income. When measured at the household level only, important intra-household variations may be masked such as differing consumption patterns at an individual level influenced by such factors as age and gender-related inequities or HIV stigma and discrimination [65]. It is not only important to understand intra-household distribution (or individual consumption), but also crucial to compare the data collected against the specific dietary needs of the HIV-infected individual which are typically higher than those of other household members.

\section{Dietary Diversity measures}

Dietary diversity measures typically look at dietary quality, but do not usually measure quantities consumed. Rather, assumptions on the nutritional adequacy of a diet are made based on the number of different food groups from which foods are consumed and on the frequency of consuming certain foods or specific food groups.

Food frequency questionnaires (FFQs) are designed to obtain qualitative or semi-quantitative descriptive information about usual food consumption patterns by assessing the frequency with which certain food groups are consumed over a particular time period [66]. Examples of these types of food consumption measures range in scope from the commonly used 98-food items Block FFQ [67] to quick categorizations based on consumption of seven culturally-based food groups [68]. In an international context, modified version of this type of questionnaire has been used by some organizations and researchers [25, 68]. Electronic forms are currently being popularized for FFQs as well in some regions such as the Guatemala's Institute of Nutrition of Central America and Panama (INCAP) electronic FFQ [69]. Although this work is not specifically related to HIV there may be lessons learnt that can be applied in HIV and food security work.

Studies that measure dietary diversity using analysis of food groupings have shown that HIV-positive people often have poor diet composition, often with high numbers of starchy foods and low numbers of protein and micronutrient-dense food [70, 71]. For example, Duran et al. [71] used repeat 24-h recalls and the Healthy Eating Index in 56 HIV-positive people living in Brazil. Mean scores were low for fruits and vegetables, dairy products, and dietary fiber. This study concluded that this population needed dietary improvements and that being overweight was associated with poorer diet quality.

Food frequency tools are highly variable and may be adapted to various populations and HIV-endemic settings [72-75]. Perhaps most notable, several studies have used the HDDS [25] or an adapted HDDS to measure dietary quality among HIV-positive people in Ethiopia [76], Malawi [77] and Uganda [68]. The HDDS is used widely programmatically and typically measures dietary diversity at household level. An adapted HDDS has also been used in connection to studies of infants and children [68, 78]. Studies that measure dietary diversity using analysis of food groupings have shown that HIV-positive people, not unlike other poor populations, often consume poor diets, characterized by high frequency of starchy foods and low frequency of protein and micronutrient-dense food types $[60,70,79,80]$. However, few if any studies compare the dietary diversity of HIV-positive and HIV-negative participants. 
Similarly to an abbreviated FFQ, the HDDS uses groupings of food into categories for example meats, dairy, vegetables, fruit, grains, pulses, fats and sugars [25]. Participants are asked whether they consumed food from any of these groups over the previous 24-h and each grouping is given a value of 1 or 0 . The strengths of this tool include that it captures some data on diet quality, while being simpler than the time-intensive and expensive food consumption measures described below. One weakness is that quantity is not captured. When people consume tiny quantities from a specific food group that may not be adequate to meet their needs, the tool will likely exaggerate the quality of their diets. This is an issue particularly in cultures where food is consumed with sauces or condiments which include ingredients from a nutritious food group, but where the quantity consumed does not result in a significant nutrient intake (for example fish sauce in Asia). Also within some food groups, one can often find a wide range of qualities which the tool cannot capture. The HDDS does not include detailed dietary intake data that would be helpful to inform individual or household level nutrition and FNS counseling or other interventions. Details of quantity, variety within food grouping and meal frequency are not captured. Nevertheless, it is often possible to draw conclusions which allow programmatic decisions. For example, when dietary diversity is poor, micronutrient deficiencies are likely (and maybe data on such deficiencies exist and can be used to triangulate) and the inclusion of a fortified staple or supplement may be justified.

Finally, another key issue with tools such as the HDDS is that they are household measures. HIV is a health condition, and the FNS picture of an HIV-infected person may differ from that of others in the household. In programs or research where PLHIV themselves are being targeted, the HDDS may best be modified to collect an individual rather than a household score. While not limited to HIV, infant and young child feeding programs face the same issue in that a child's needs differ a lot from those of other household members and intra-household distribution may affect intake. This has led WHO to recommend collecting dietary diversity at the individual level for infants and young children. WHO has developed a specific tool to capture these data, entitled "Indicators for assessing infant and young child feeding practices" [81].

\section{Food Safety}

The concept of food safety security is gaining momentum in the context of global efforts towards surveillance of microbial and chemical contamination of food [82-84]. However, in the context of HIV research and programming, issues of food safety and hygiene for adults and children have often been overlooked. This is despite the fact that from the early days of the HIV epidemic the often resulting gastrointestinal symptoms are estimated to be twice as prevalent in patients in developing countries than in the US or Europe. Pregnant and lactating women, children, the elderly, people who are chronically ill and/or malnourished may be at increased risk of poor food safety [85]. Populations of PLHIV are particularly susceptible to the outcomes of poor food safety such as foodborne pathogenic infections due to their immuno-compromised state. They are also potentially more vulnerable if their health is compromised by socio-economic and environmental factors such as poor hygiene practices and sanitation and lack of food safety education.

Studies on food safety among people living with HIV/ AIDS can be broadly described as falling into two methodological areas: laboratory-based microbial and toxicological studies of susceptibility; and epidemiological and behavioral studies of vulnerability. Laboratory-based evaluations of food safety among PLHIV suggest that prevalence of food borne diseases may be elevated in this population. For example, early on in the HIV epidemic, salmonellosis was estimated to be nearly 20 times more common and 5 times more bacteremic in AIDS patients than those without AIDS [86]. A study in South Africa 2001-2002 found that 48 of $60 \mathrm{HIV}$-positive patients with chronic diarrhea had bacterial pathogens [87]. PLHIV with a lower CD4 count are more immune suppressed and more vulnerable to all infections, including food and water-borne infections.

Knowledge, attitudes, and beliefs of PLHIV, food service providers, and others involved in the production and distribution of food may be used to measure food safety in the context of HIV using standard surveys or observation [88]. Other types of measures for food safety include behavioural measures (e.g., hand-washing), household measures (e.g., plumbed toilets) those involved in the management of food production systems (workplace sanitation), food and water sources (e.g., bacterial thresholds in meat), and programmatic adherence to food safety guidelines such as Hazard Analysis and Critical Control Points (HACCP) supported and used by agencies such as the USDA and the FDA. Global measures of sanitation also exist which may be used and adapted for populations of PLHIV. To our knowledge, only one measurement tool has been validated in a population of PLHIV in Brazil which assessed knowledge, perceptions, and behaviours related to food safety [89]. What few studies exist deal primarily with surveys of self-reported knowledge of food safety measures and hand-washing. Studies have shown that PLHIV lack knowledge of food safety measures [90]. In Ghana, Wiig and Smith [79] (2007) found that only $22 \%$ of PLHIV boiled their water and only $66 \%$ always reheated leftovers. 
Heathcock's [90] (1998) self-developed survey of 77 HIVpositive people in a hospitalized UK-based population showed that 96,66 , and $23 \%$ were aware of the risk of infection from Salmonella, Listeria, and Cryptosporidium, respectively, but few were aware of infections transmitted through water. Program evaluation studies in the US have found home-delivered meal programs for PLHIV to be strongly adherent to food safety guidelines and have evaluated the effectiveness of educational tools [91].

The area of food safety survey tools tailored to immunocompromised populations such as PLHIV and their higher degree of risk of exposure is poorly developed and it is evident that more valid and reliable food safety riskassessment scales are required. Food safety should be seen as a component of FNS assessment that is extremely important for PLHIV, although it would rarely be used as an exclusive measure of FNS for programmatic or research purposes. These tools would measure knowledge, attitudes and behaviours around food safety for PLHIV to assess the likelihood of problems with food safety, for example microbiological contamination of food and water. Without lab analysis of food, water, blood and stool samples the information collected will only provide an assessment of risk, not actual incidence of food-borne illness.

\section{Multidimensional Measures}

Food consumption assessment tools allow for the measurement of two of the three main sub-components of food insecurity, namely, dietary sufficiency and diversity. Food safety is often set apart from other dietary measures of FNS and therefore remains unidimensional in its assessment. The multidimensional tools collect data on actual food consumed by individuals or households over a set period of time and provide detailed data about energy, macronutrient and micronutrient intake and/or food groupings. Food consumption measures are often used in combination with each other [92, 93]. The major advantage of using these tools is that they can provide a much more complete picture of dietary intake, both in terms of what is eaten and how much of it. When collected at the individual level, they provide all necessary data to compare actual consumption to the individual dietary needs which differ by age, gender, physiological status, disease stage and level of physical activity. The two dietary intake assessment techniques most commonly described in the HIV literature are 24-h recall and food records. For both food records and 24-h recall, extensive investment must be made up-front to ensure that recipes and portion sizes of local foods are well defined [33].

When analyzing and interpreting food consumption data for PLHIV, it is important to consider their nutritional needs. PLHIV are not specifically recommended to increase their intake of any one macro- or micronutrient, but instead, their diet intake should be comprised of the same proportions as recommended for HIV-negative people. Increased energy intake should result in PLHIV consuming higher absolute amounts of each of the macronutrients in proportion [6, 94]. Individual nutrient intakes such as energy (kcals) in the evaluation of food sufficiency or various micronutrients in the evaluation of dietary diversity may also be compared against population and national norms or established standards such as the FAO/WHO Recommended Nutrient Intakes (RNI) and the more recently published North American Dietary Reference Intakes (DRI).

When sufficient resources exist, both 24-h recall and food records are feasible among PLHIV. They can be implemented as they are in other populations and can provide quality information, especially in terms of comparing food consumption to the specific dietary needs of PLHIV at the individual and population levels. Another interesting application could be to better understand to what extent HIV can induce food and nutrition insecurity by comparing the food security of HIV-affected households with those that are deemed not affected.

\section{4-h Recall}

24-h recalls may be used in a clinical or research context to solicit information about food consumption for a 24-h period (usually the preceding day while memories remain more intact). The popularity of this tool is due to the fact that it is administered as part of an interview and that it does not require detailed record-keeping, weighing, or high levels of literacy or numeracy. Detailed descriptions of how to administer 24-h dietary recall have been published elsewhere [66]. The USDA developed and validated the 5-step multi-pass method for this purpose which poses tailored questions in an ordered sequence [95, 96]. With web-based technologies, this method has evolved into the "automated multi-pass method" used and validated as part of the longitudinal US-based National Health and Nutrition Examination Survey (NHANES) study. Web-based tools are evolving to engage with study participants more directly such as the American user-friendly web-based interface of the ASA24 [97]. Given technological advances and the rapid expansion of electronic and mobile health in both high and low-resource settings, similar tools may have practical and feasible application globally.

Literature on the use of the 24-h recall in HIV-positive populations is limited especially in HIV-endemic countries. This is likely due to the constraints imposed regarding technical skills, time, and costs of analysis. Becquet et al. [98] and Fadnes et al. [99] describe studies of infant feeding with HIV-positive mothers from the Côte d'Ivoire. 
This combined reports of breastfeeding with lists of potential complementary foods consumed over a 24-h period. Arising from this work, Becquet et al. [98] (2006) created a child feeding index for HIV-exposed children, to assess nutritional adequacy in terms of quality of milk source, dietary diversity, food and meal frequencies. More recently, a food insecurity study in Ghana of a cross sectional infant health observational cohort incorporated the 24-h recall to assess diet in a sample of HIV-positive and non-infected lactating women [100]. Using repeat 24-h food records inputted into nutrient software with Ghana food composition tables, they found that energy intake was independently associated with their validated food insecurity scale (the USDA Household Core Module). Onyango et al. [70] used a combination of 24-h recall and FFQ with HIV affected and non-affected households in Kenya and showed that the percentage of RDA consumed for almost all nutrients were higher for the non-HIV-affected households than for those with HIV. 24-h dietary recalls have also been used in the context of HIV-positive and negative drug using cohorts in the US, in combination with other food consumption measures, to ascertain possible association between BMI and dietary intake [93].

The $24 \mathrm{~h}$ recall has shown to be valid for use among people with low levels of literacy, and has been effectively used in vulnerable populations including PLHIV who use drugs and those that live in HIV-endemic regions [70, 93]. Some disadvantages associated with this tool are that it prone to high intra-subject variability, requiring multiple recalls in order to obtain an accurate estimate of average nutrient intake. The 24-h dietary recall is therefore timeand resource-intensive. Furthermore, the tool requires well trained interviewers in order to reduce measurement and recall bias.

\section{Food Records}

Food records, specifically 3-day food records, are considered the gold standard for dietary intake assessment [66]. The methodology involves asking a participant to track and record their food consumption over a predetermined period of time. Unlike in the recall, where a participant is interviewed and the enumerator captures verbal responses to a pre-established questionnaire ex post, here participants are asked ex ante to provide detailed written accounts of the food that they consumed including more precise measurement of food weights and portion sizes. These additional details aid in determining nutrient intake with more accuracy while also measuring usual intake. Use of food records in the context of HIV is reported in the HIV literature as part of the Americanbased Nutrition for a Healthy Living Study (NHLS). However, as this methodology requires high levels of literacy, numeracy, and overall commitment, it is often impractical in programmatic settings and inappropriate for the key populations. For example, Sahni and colleagues determined that this method was not ideal for drug using US populations of PLHIV [101].

Food records may be deemed more precise as recording allows to capture a longer period of time and there may be less recall bias. However, study participants need to be literate and checklists need to be very simple and unequivocal so as to reduce the likelihood of mistakes. There is no interviewer who can make sure the information requested is adequately understood. One can also argue that food records require a greater effort by participants and the simple fact of monitoring food consumption daily may change it.

Tools that measure aspects of food being consumed, including 24-h recalls and food records have some powerful strengths when assessing FNS for PLHIV. They provide detailed data regarding dietary sufficiency and diversity. Although nutritional intake and safety are always an important component of FNS, this is particularly true for PLHIV. PLHIV are not only vulnerable to the social and environmental causes of food insecurity, they also have heightened physical risks of developing malnutrition, due to increased nutritional needs from infection, side effects of medications and possible occurrences of mouth sores or diarrhea. The data captured using these tools is well suited for research of food consumption-related issues and to (where resources are available) individual counseling and management of nutrition and FNS for PLHIV. These tools are not well suited for rapid assessments, programme evaluations or for ongoing monitoring and evaluation because of the equipment and highly trained staff required, the complex analysis and the level of literacy and numeracy required of participants. When nutrition analysis software does not contain culturally-representative foods, it is crucial to add these so as to be able to truly reflect local diets. Finally, it is important to triangulate the results with those from other analyses. This may also allow to better understand what may cause the observed behaviours.

\section{Conclusions}

Food and nutrition security are important and interlinked concepts in HIV-endemic settings and for PLHIV. Measurement of FNS is, however, complex and selection of appropriate, complementary tools is of paramount importance to ensure data quality. In selecting an assessment tool users must consider which sub-types of FNS they wish to measure (food sufficiency, dietary diversity and/or food safety); the inherent strengths and weaknesses in each tool; if they are collecting information at population, household 
or individual level; and the available time, money and human resources. Tool users must also consider if they require a validated tool for research or evaluation purposes. Tools may require modification to ensure they are locally appropriate, for example modifying the number and content of food groups and ensuring access to locally accurate food composition tables. Analysis and interpretation of nutrient data must be sensitive to the increased nutritional demands of HIV infection, whether asymptomatic or suffering from opportunistic infections, as well as the demands of pregnancy and lactation. PLHIV are vulnerable to the effects of food-borne illness and food safety assessment is an important factor in this population. Food supplementation for PLHIV is expensive and competes with other potential interventions for already-constrained resources. The global move to standardize FNS program monitoring and evaluation indicators for HIV and the need for better data to inform food and nutrition program planning for PLHIV and in HIV-endemic settings are both important drivers to ensure that there are appropriate and sensitive assessment tools available. Measurement tools need to be validated among PLHIV in both low and high resource settings, in different cultural contexts, with key populations and with both genders to build a more comprehensive knowledge base.

It is the opinion of these authors that generalized survey measurement tools and unidimensional dietary diversity tools are the strongest tools for use in programmatic applications; for example needs assessments, program evaluations and ongoing monitoring and evaluation. Many of these tools have been validated in HIV-endemic settings and are inexpensive and quick to administer. They do not require highly specialized staff or a high level of literacy among participants. Food consumption measurement tools are better suited for research application where there is a strong nutritional component to the research question, or for clinical management of nutrition and FNS of individual patients by highly trained staff.

A key factor in improving FNS for PLHIV globally is using the correct tools to assess FNS and measure improvement over time and in the context of program delivery and policy roll-out. There is an opportunity to develop consensus on the use of tools in FNS assessment for PLHIV. International stakeholders should move forward with recommendations and standardization to improve program integration, measurement and effectiveness.

Acknowledgments The authors wish to acknowledge the support of Sebastian Stricker and the World Food Program for their stewardship of the journal special issue. We would like to thank Tony Castleman (George Washington University) for clarifying aspects of FANTA measurement tools.

Conflict of interest None.

\section{References}

1. Weiser SD, Young SL, Cohen CR, Kushel MB, Tsai AC, Tien PC, Hatcher AM, Frongillo EA, Bangsberg DR. Conceptual framework for understanding the bidirectional links between food insecurity and HIV/AIDS. Am J Clin Nutr. 2011;94(6): 1729S-39S.

2. Anema A, Vogenthaler N, Frongillo EA, Kadiyala S, Weiser SD. Food insecurity and HIV/AIDS: current knowledge, gaps, and research priorities. Curr HIV/AIDS Rep. 2009;6(4):224-31.

3. United Nations General Assembly. United to end AIDS: achieving the targets of the 2011 Political Declaration Report of the Secretary-General Sixty-fifth session. Agenda item 10. April 2012.

4. Anema A, Fielden SJ, Castelman T, Grede N, Heap A, Bloem M. Food insecurity in the context of HIV: towards harmonized definitions and indicators AIDS and behavior (under review). 2013.

5. Chandrasekhar A, Gupta A. Nutrition and disease progression pre-highly active antiretroviral therapy (HAART) and postHAART: can good nutrition delay time to HAART and affect response to HAART? Am J Clin Nutr. 2011;94(suppl):1703S15S.

6. de Pee S, Semba RD. Role of nutrition in HIV infection: review of evidence for more effective programming in resource-limited settings. Food Nutr Bull. 2010;31(4):S313.

7. Raiten DJ, Mulligan K, Papathakis P, Wanke C. Executive summary: nutritional care of HIV-infected adolescents and adults, including pregnant and lactating women: what do we know, what can we do, and where do we go from here? Am J Clin Nutr. 2011;94(6):1667S-76S.

8. American Dietetic Association (ADA). Position of the American Dietetic Association: nutrition intervention and human immunodeficiency virus infection. JAIDS. 2010;110:1105-19.

9. Semba RD, Caiaffa WT, Graham NM, Cohn S, Vlahov D. Vitamin A deficiency and wasting as predictors of mortality in human immunodeficiency virus-infected injection drug users. J Infect Dis. 1995;171:1196-202.

10. Tang AM, Graham NM, Chandra RK, Saah AJ. Low serum Vitamin B-12 concentrations are associated with faster human immunodeficiency virus type 1 (HIV-1) disease progression. J Nutr. 1997;127(2):345-51.

11. Baum MK. Role of micronutrients in HIV-infected intravenous drug users. J Acquir Immune Defic Syndr. 2000;25(Suppl 1): S49-52.

12. Batteram MJ. Investigating heterogeneity in studies of resting energy expenditure in person with HIV/AIDS: a meta-analysis. Am J Clin Nutr. 2005;81:702-13.

13. Coyne-Meyers K, Trombley LE. A review of nutrition in human immunodeficiency virus infection in the era of highly active antiretroviral therapy. Nutr Clin Pract. 2004;19(4):340-55.

14. Hayes C, Elliot E, Krales E, Downer G. Food and water safety for persons infected with human immunodeficiency virus. Clin Infect Dis. 2003;36(Suppl 2):S106-9.

15. Wanke C, Polsky B, Kotler D. Guidelines for using body composition measurement in patients with human immunodeficiency virus infection. AIDS Patient Care STDs. 2002;16(8): 375-88.

16. Abrahams Z, McHiza Z, Steyn NP. Diet and mortality rates in Sub-Saharan Africa: stages in the nutrition transition. BMC Public Health. 2011;11:801.

17. Semba RD, Shah N, Vlahov D. Improvement of anemia among HIV-infected injection drug users receiving highly active antiretroviral therapy. J Acquir Immune Defic Syndr. 2001;26(4): 315-9. 
18. Verweel G, van Rossum AM, Hartwig NG, Wolfs TF, Scherpbier HJ, de Groot R. Treatment with highly active antiretroviral therapy in human immunodeficiency virus type 1-infected children is associated with a sustained effect on growth. Pediatrics. 2002;109(2):E25.

19. Drain PK, Kupka R, Mugusi F, Fawsi WW. Micronutrients in HIV-positive persons receiving highly active antiretroviral therapy. Am J Clin Nutr. 2007;85:333-45.

20. Schwenk A, Beisenherz A, Kremer G, Diehl V, Salzberger B, Fatkenheuer G. Bioelectrical impedance analysis in HIV-infected patients treated with triple antiretroviral treatment. Am J Clin Nutr. 1999;70(5):867-73.

21. Bavinger C, Bendavid E, Niehaus K, Olshen RA, Olkin I, Sundaram V, et al. Risk of cardiovascular disease from antiretroviral therapy for HIV: a systematic review. PLoS ONE. 2013;8(3):e59551.

22. Martin CP, Fain MJ, Klotz SA. The older HIV-positive adult: a critical review of the medical literature. Am J Med. 2008;121(12): 1032-7.

23. Smith RD, Delpech VC, Brown AE, Rice BD. HIV transmission and high rates of late diagnoses among adults aged 50 years and over. AIDS. 2010;24(13):2109-15.

24. Frega R, Duffy F, Rawat R, Grede N. Food insecurity in the context of HIV/AIDS: a framework for a new era of programming. Food Nutr Bull. 2010;31(4):S292.

25. Swindale A, Bilinsky P, Food and Nutrition Technical Assistance (FANTA). Household dietary diversity score (HDDS) for measurement of household food access: indicator guide. Version 2. 2006. http://www.fantaproject.org/publications/hdds_mahfp. shtml. Accessed 25 Nov 2013.

26. Turan JM, Nyblade L. HIV-related stigma as a barrier to achievement of global PMTCT and maternal health goals: a review of the evidence. AIDS Behav. 2013;17:2528.

27. Pellowski JA. Barriers to care for rural people living with HIV: a review of domestic research and health care models. J Assoc Nurses AIDS Care. 2013;24:422.

28. Herdt G. Stigma and the ethnographic study of HIV: problems and prospects. AIDS Behav. 2001;5(2):141-9.

29. Herek GM. AIDS and Stigma. Am Behav Sci. 1999;42(7): 1106-16.

30. Crandall CS, Glor J, Britt TW. AIDS-related stigmatization: instrumental and symbolic attitudes. J Appl Soc Psychol. 1997; 27(2):95-123.

31. Stein MD, Crystal S, Cunningham WE, Ananthanarayanan A, Andersen RM, Turner BJ, et al. Delays in seeking HIV care due to competing caregiver responsibilities. Am J Public Health. 2000;90(7):1138-40.

32. Anema A, Wood E, Weiser SD, Qi J, Montaner JS, Kerr T. Hunger and associated harms among injection drug users in an urban Canadian setting. Subst Abuse Treat Prev Policy. 2010;5: 20.

33. Hoddinott J. Choosing outcomes indicators of household food security. international food and policy research institute (IFPRI). 1999. Technical Guide \#7. http://www.ifpri.org/sites/default/ files/publications/tg07.pdf. Accessed 27 Feb 2013.

34. United States Department of Agriculture (USDA). Food insecurity and hunger in the United States: An assessment of the measure. Panel to Review the U.S. Department of Agriculture's Measurement of Food Insecurity and Hunger. Wunderlich GS, Norwood JL Editors. The National Academies Press. Washington DC. 2006. http://www.nap.edu/catalog/11578.html. Accessed 19 Feb 2013

35. Radimer KL, Radimer KL. Measurement of household food security in the USA and other industrialised countries. Public Health Nutr. 2002;5(6A):859-64.
36. Swindale A, Bilinsky P, Food and nutrition technical assistance (FANTA)-2. Months of adequate household food provisioning (MAHFP) for measurement of household food access: indicator guide. Version 4. 2010. http://www.fantaproject.org/publications/ hdds_mahfp.shtml. Accessed 25 Nov 2013.

37. Wiesmann D, Bassett L, Benson T, Hoddinott J. Validation of the World Food Programme's Food Consumption Score and Alternative Indicators of Household Food Security. IFPRI Discussion Paper 00870. 2009.

38. Coates J, Swindale A, Bilinsky P. Household food insecurity access scale (HFIAS) for measurement of household food access: indicator guide. Version 3. 2007. http://www.fantaproject.org/publications/ hfias_intro.shtml. Accessed 27 Feb 2013.

39. Statistics Canada. Canadian Community Health Survey (CCHS), Cycle 2.2, Nutrition (2004): Income-related household food security in Canada. Available 2012. http://www.hc-sc.gc.ca/fnan/surveill/nutrition/commun/income_food_sec-sec_alim-eng.php\# metho24. Accessed 17 Dec 2012.

40. Food and nutrition technical assistance (FANTA)-2. Household hunger scale. USAID. 2011 http://www.fantaproject.org/publica tions/hhs_2011.shtml. Accessed 24 Feb 2012.

41. FANTA. Household food insecurity access scale for measurement of food access: indicator guide, Version 3. http://www. fantaproject.org/focus/foodsecurity.shtml. Accessed $27 \mathrm{Feb}$ 2013.

42. Anema A, Weiser SD, Fernandes KA, Ding E, Brandson EK, Palmer A, Montaner JS, Hogg RS. High prevalence of food insecurity among HIV-infected individuals receiving HAART in a resource-rich setting. AIDS Care. 2009;23(2):221-30.

43. Normén L, Chan K, Braitstein P, Anema A, Bondy G, Montaner JS, Hogg RS. Food insecurity and hunger are prevalent among HIV-positive individuals in British Columbia. Canada $\mathbf{J}$ Nutr. 2005;135(4):820-5.

44. Weiser SD, Fernandes KA, Brandson EK, Lima VD, Anema A, Bangsberg DR, Montaner JS, Hogg RS. The association between food insecurity and mortality among HIV-infected individuals on HAART. J Acquir Immune Defic Syndr. 2009;52(3):342-9.

45. Shannon K, Kerr T, Milloy MJ, Anema A, Zhang R, Montaner JS, Wood E. Severe food insecurity is associated with elevated unprotected sex among HIV-seropositive injection drug users independent of HAART use. AIDS. 2011;25(16):2037-42.

46. McMahon JH, Wanke CA, Elliott JH, Skinner S, Tang AM. Repeated assessments of food security predict CD4 change in the setting of antiretroviral therapy. J Acquir Immune Defic Syndr. 2011;58(1):60-3.

47. Weiser SD, Bangsberg DR, Kegeles SK, Ragland K, Kushel $\mathrm{MB}$, Frongillo EA. Food insecurity among homeless and marginally housed individuals living with HIV/AIDS in San Francisco. AIDS Behav. 2009;13(5):841-8.

48. Wang EA, McGinnis KA, Fiellin DA, Goulet JL, Bryant K, Gibert CL, Leaf DA, Mattocks K, Sullivan LE, Vogenthaler N, Justice AC, VACS Project Team. Food insecurity is associated with poor virologic response among HIV-infected patients receiving antiretroviral medications. J Gen Intern Med. 2011; 26(9):1012-8.

49. Samuels FA, Rutenberg N. Health regains but livelihoods lag: findings from a study with people on ART in Zambia and Kenya. AIDS Care. 2011;23(6):748-54.

50. Nagata JM, Magerenge RO, Young SL, Oguta JO, Weiser SD, Cohen CR. Social determinants, lived experiences, and consequences of household food insecurity among persons living with HIV/AIDS on the shore of Lake Victoria, Kenya. AIDS Care. 2012;24(6):728-36.

51. Tsai AC, Bangsberg DR, Frongillo EA, Hunt PW, Muzoora C, Martin JN, Weiser SD. Food insecurity, depression and the 
modifying role of social support among people living with HIV/ AIDS in rural Uganda. Soc Sci Med. 2012;74(12):2012-9.

52. Sunguya BF, Poudel KC, Otsuka K, Yasuoka J, Mlunde LB, Urassa DP, Mkopi NP, Jimba M. Undernutrition among HIVpositive children in Dar es Salaan, Tanzania: antiretroviral therapy alone is not enough. BMC Public Health. 2011;11:869.

53. Tang AM, Sheehan HB, Jordan MR, Van Duong D, Terrin N, Dong K, Thi Minh Lien T, Vu Trung N, Wanke CA, Duc Hien $\mathrm{N}$. Predictors of weight change in male HIV-positive injection drug users initiating antiretroviral therapy in Hanoi, Vietnam. AIDS Res Treat. 2011. doi:10.1155/2011/890308.

54. Bilukha OPC, Moloney G, Hailey P, Doledec D. Measuring anthropometric indicators through nutrition surveillance in humanitarian settings: options, issues, and ways forward. Food Nutr Bull. 2012;33(2):169-76.

55. Alaimo K, Briefel RR, Frongillo EA Jr, Olson CM. Food insufficiency exists in the United States: results from the third National Health and Nutrition Examination Survey (NHANES III). Am J Public Health. 1998;88(3):419-26.

56. Rose D. Economic determinants and dietary consequences of food insecurity in the United States. J Nutr. 1999;129(2S Suppl):517S-20S.

57. Parenteau J, Edelman D, Glynn K, House A. Nutrition guidelines for agencies providing food to people living with HIV disease. Washington, DC: Association of Nutrition Services Agencies (ANSA); 2002.

58. Association of Nutrition Services Agencies (ANSA). Nutrition guidelines for agencies providing food to people living with HIV disease. Second Edition. 2002. www.aidsnutrition.org/documents/ ansanutritionguides.pdf. Accessed 27 Feb 2012.

59. Fan S. Improving food and nutrition security information for better measurement and effective decision-making. 2012 International Scientific Symposium on Food and Nutrition Security: "From valid measurement to effective decision making", Rome, 17-18 January 2012.

60. Duran AC, Almeida LB, Segurado AA, Jaime PC. Diet quality of persons living with HIV/AIDS on highly active antiretroviral therapy. J Hum Nutr Diet. 2008;21(4):346-50.

61. Kimani-Murage EW. Exploring the paradox: double burden of malnutrition in rural South Africa. Glob Health Action. 2013;6: $1-13$.

62. Black RE, Allen LH, Bhutta ZA, Caulfield LE, de Onis M, Ezzati M, et al. Maternal and child undernutrition: global and regional exposures and health consequences. Lancet. 2008; 371(9608):243-60.

63. Victora CG, Adair L, Fall C, Hallal PC, Martorell R, Richter L, et al. Maternal and child undernutrition: consequences for adult health and human capital. Lancet. 2008;371(9609):340-57.

64. Anema A MD, Weiser SD, Grede N, Kerr T. Drivers and consequences of food insecurity among illicit drug users: an evidence-based framework (unpublished).

65. Hyder AA, Maman S, Nyoni JE, Khasiani SA, Teoh N, Premji $\mathrm{Z}$, et al. The pervasive triad of food security, gender inequity and women's health: exploratory research from sub-Saharan Africa. Afr Health Sci. 2005;5(4):328-34.

66. Gibson RS. Principles of Nutritional Assessment. 2nd ed. Oxford: Oxford University Press; 2005.

67. Block G, Hartman A, Dresser CM, Carroll MD, Gannon J, Gardner L. A data-based approach to diet questionnaire design and testing. Am J Epidemiol. 1986;124(3):453-69.

68. Bukusuba J, Kikafunda JK, Whitehead RG. Food security status in households of people living with HIV/AIDS (PLWHA) in a Ugandan urban setting. Br J Nutr. 2007;98(1):211-7.

69. Organization. WFPaFaA. Measures of food consumption-harmonizing methodologies. Rome: 2008 9-10 April 2008.
70. Onyango AC, Walingo MK, Othuon L. Food consumption patterns, diversity of food nutrients and mean nutrient intake in relation to HIV/AIDS status in Kisumu district Kenya. Afr J AIDS Res. 2009;8(3):359-66.

71. Duran AC, Almeida LB, Segurado AA, Jaime PC. Diet quality of persons living with HIV/AIDS on highly active antiretroviral therapy. J Hum Nutr Diet. 2008;21:346-50.

72. Ruel MT. Operationalizing dietary diversity: a review of measurement issues and research priorities. J Nutr. 2003;133: 3911S-26S.

73. Kant AK. Indexes of overall diet quality: a review. J Am Diet Assoc. 1996;96(8):785-91.

74. Kant AK, Schatzkin A, Harris TB, Ziegler RG, Block G. Dietary diversity and subsequent mortality in the First National Health and Nutrition Examination Survey Epidemiologic Follow-up Study. Am J Clin Nutr. 1993;57(3):434-40.

75. Hoddinott JYY. Dietary diversity as a household food security indicator. Washington, DC: FANTA; 2002.

76. Tiyou Ayele, Belachew Tefera, Alemseged Fisehaye, Biadgilign Sibhatu. Food insecurity and associated factors among HIVinfected individuals receiving highly active antiretroviral therapy in Jimma zone Southwest Ethiopia. Nutr J. 2012;11:51.

77. Bahwere P, Deconinck H, Banda T, Mtimuni A, Collins S. Impact of household food insecurity on the nutritional status and the response to therapeutic feeding of people living with human immunodeficiency virus. Patient Prefer Adherence. 2011;5: 619-27.

78. Magezi SR, Kikafunda J, Whitehead R. Feeding and nutritional characteristics of infants on PMTCT programs. J Trop Pediatr. 2009;55(1):32-5.

79. Wiig K, Smith C. An exploratory investigation of dietary intake and weight in human immunodeficiency virus-seropositive individuals in Accra, Ghana. JAIDS. 2007;107:1008-13.

80. Joy TKH, Hadigan C, Lee H, Dolan SE, Fitch K, et al. Dietary fat intake and relationship to serum lipid levels in HIV-infected patients with metabolic abnormalities in the HAART era. AIDS. 2007;21:1591-600.

81. WHO. Indicators for assessing infant and young child feeding practices. Washington, DC: World Health Organisation; 2010.

82. Iyengar V, Elmadfa I. Food safety security: a new concept for enhancing food safety measures. Int J Vitam Nutr Res. 2012; 82(3):216-22.

83. World Health Organization (WHO). Global strategy for food safety: safer food for better health. Geneva: WHO; 2001.

84. World Health Organization (WHO). Global environment monitoring system/food contamination monitoring and assessment programme (GEMS/Food). Geneva: WHO; 2010.

85. Smith PD, Quinn TC, Strober W, Janoff EN, Masur H, NIH conference. Gastrointestinal infections in AIDS. Ann Intern Med. 1992;116(1):63-77.

86. Celum CL, Chaisson RE, Rutherford GW, Barnhart JL, Echenberg DF. Incidence of salmonellosis in patients with AIDS. J Infect Dis. 1987;156(6):998-1002.

87. Obi CL, Bessong PO. Diarrhoeagenic bacterial pathogens in HIV-positive patients with diarrhoea in rural communities of Limpopo Province, South Africa. J Health Popul Nutr. 2002; 20(3):230-4.

88. Kendall P, Medeiros LC, Hillers V, Chen G, DiMascola S. Food handling behaviors of special importance for pregnant women, infants and young children, the elderly, and immune-compromised people. J Am Diet Assoc. 2003;103:1646-9.

89. Leite Maia L, Waissmann W, Veggi A. Reproducibility of a questionnaire to assess knowledge, perceptions, and practices of food safety in patients with HIV/AIDS outpatient. Bull World Health Organ. 2007;23(4). 
90. Heathcock R, McLauchlin J, Newton LH, Soltanpoor N, Coker $\mathrm{R}$, Bignardi $\mathrm{G}$, et al. Survey of food safety awareness among HIV positive individuals. AIDS Care. 1998;10(2):237-41.

91. Hoffman EW, Bergmann V, Shultz JA, Kendall P, Medeiros LC, Hillers VN. Application of a five-step message development model for food safety education materials targeting people with HIV/AIDS. J Am Diet Assoc. 2005;105(10):1597-604.

92. Hu W, Jiang H, Chen W, Sheng-Hua H, Deng B, Wang WY, et al. Malnutrition in hospitalized people living with HIV/AIDS: evidence from a cross-sectional study from Chengdu, China. Asia Pac J Clin Nutr. 2011;20(4):544-50.

93. Forrester JE, Tucker KL, Gorbach SL. Dietary intake and body mass index in HIV-positive and HIV-negative drug abusers of Hispanic ethnicity. Public Health Nutr. 2004;7(7):863-70.

94. Hsu JWC, Pencharz PB, Macallan D, Tomkins A. Macronutriennts and HIV/AIDS: a review of current evidence. Consultation on nutrition and HIV/AIDS in Africa: Evidence, lessons and recommendations for action. Durban, South Africa: World Health Organization, Department of Nutrition for Health and Development, 2005.

95. Moshfegh AJ, Rhodes DG, Baer DJ, Murayi T, Clemens JC, Rumpler WV, et al. The US Department of Agriculture Automated Multi-Pass Method reduces bias in the collection of energy intakes. Am J Clin Nutr. 2008;88:324-32.

96. United States Department of Agriculture (USDA). What we eat in America, NHANES. Agricultural Research Service, U.S. Department of Agriculture 2012. http://www.ars.usda.gov/ Services/docs.htm?docid=13793. Accessed 25 Nov 2013.

97. Thompson FE, Subar AF, Loria CM, Reedy JL, Baranowski T. Need for technological innovation in dietary assessment. JADA. 2010;110(1):48-51.

98. Becquet R, Leroy V, Ekouevi DK, Viho I, Castetbon K, Fassinou P, Dabis F, Timite-Konan M, ANRS 1201/1202 Ditrame Plus Study Group. Complementary feeding adequacy in relation to nutritional status among early weaned breastfed children who are born to HIV-infected mothers: aNRS 1201/1202 Ditrame Plus, Abidjan, Cote d'Ivoire. Pediatrics. 2006;117(4):e701-10.

99. Fadnes LT, Engebretsen IMS, Wamani H, Semiyaga NB, Tylleskar T, Tumwine JK. Infant feeding among HIV-positive mothers and the general population mothers: comparison of two cross-sectional surveys in Eastern Uganda. BMC Public Health. 2009;9:124-38.

100. Addo AA, Marquis GS, Lartey AA, Pérez-Escamilla R, Mazur RE, Harding KB. Food insecurity and perceived stress but not HIV infection are independently associated with lower energy intakes among lactating Ghanaian women. Matern Child Nutr. 2011;7(11):80-91.

101. Sahni S, Forrester JE, Tucker KL. Assessing dietary intake of drug-abusing hispanic adults with and without human immunodeficiency virus infection. J Am Diet Assoc. 2007;107(6): 968-76.

102. Deitchler M, Ballard T, Swindale A, Coates J. Validation of a measure of household hunger for cross-cultural use. Washington, DC: Food and Nutrition Technical Assistance II Project (FANTA-2); 2010.

103. Becquey E, Martin-Prevel Y, Traissac P, Dembele B, Bambara A, Delpeuch F. The household food insecurity access scale and an index-member dietary diversity score contribute valid and complementary information on household food insecurity in an urban West-African setting. J Nutr. 2010;140(12):2233-40.

104. Knueppel D, Demment M, Kaiser L. Validation of the Household Food Insecurity Access Scale in rural Tanzania. Public Health Nutr. 2010;13(3):360-7.

105. Swindale A, Bilinsky P. Development of a universally applicable household food insecurity measurement tool: process, current status, and outstanding issue. J Nutr. 2006;136(5): 1449S-52S.

106. Perez-Escamilla R, Segall-Correa AM, Kurdian Maranha L, Sampaio Md Mde F, Marin-Leon L, Panigassi G. An adapted version of the U.S. Department of Agriculture Food Insecurity module is a valid tool for assessing household food insecurity in Campinas, Brazil. J Nutr. 2004;134(8):1923-8.

107. Derrickson JP, Anderson JA, Fisher A. The Core Food Security Module scale measure demonstrates validity and reliability when used with Asians and Pacific Islanders. J Nutr. 2000;130: 2666-74.

108. Blumberg S, Bialostosky K, Hamilton WL, Briefel RR. The effectiveness of a short form of the Household Food Security Scale. Am J Public Health. 1999;89:1231-4.

109. Frongillo EA, Rauschenbach BS, Olson CM, Kendall A, Colmenares AG. Questionnaire-based measures are valid for the identification of rural households with hunger and food insecurity. J Nutr. 1997;127:699-705.

110. Frongillo EA Jr. Validation of measures of food insecurity and hunger. J Nutr. 1999;129(2S Suppl):506S-9S.

111. Opsomer JD, Jensen HH, Pan S. An evaluation of the U.S. Department of Agriculture food security measure with generalized linear mixed models. J Nutr. 2003;133(2):421-7.

112. Gulliford MC, Mahabir D, Nunes C, Rocke B. Self-administration of a food security scale by adolescents: item functioning, socio-economic position and food intakes. Public Health Nutr. 2005;8(7):853-60.

113. Hromi-Fiedler A, Bermudez-Millan A, Melgar-Quinonez H, Perez-Escamilla R. Psychometric Properties of an Adapted Version of the U.S. Household Food Security Survey Module for Assessing Food Insecurity Among Low-Income Pregnant Latinas. J Hunger Environ Nutr. 2009;4(1):81-94.

114. Hromi-Fiedler A, Bermudez-Millan A, Segura-Perez S, Damio G, Perez-Escamilla R, 1. Adaptation of the U.S. food security survey module for low-income pregnant Latinas: qualitative phase. J Hunger Environ Nutr. 2009;4(1):62-80.

115. Rafiei M, Nord M, Sadeghizadeh A, Entezari MH. Assessing the internal validity of a household survey-based food security measure adapted for use in Iran. Nutr J. 2009;8:28.

116. Munoz-Astudillo MN, Martinez JW, Quintero AR. Validating Latin-American and Caribbean Latin-American food security scale on pregnant adolescents. Rev Salud Publica (Bogota). 2010;12(2):173-83.

117. Gulliford MC, Nunes C, Rocke B. The 18 Household Food Security Survey items provide valid food security classifications for adults and children in the Caribbean. BMC Public Health. 2006;6:26.

118. Nord M, Hopwood H. Recent advances provide improved tools for measuring children's food security. J Nutr. 2007;137(3):533-6.

119. Connell CL, Nord M, Lofton KL, Yadrick K. Food security of older children can be assessed using a standardized survey instrument. J Nutr. 2004;134(10):2566-72.

120. Shoae NZ, Omidvar N, Ghazi-Tabatabaie M, Houshiar Rad A, Fallah H, Mehrabi Y. Is the adapted Radimer/Cornell questionnaire valid to measure food insecurity of urban households in Tehran, Iran? Public Health Nutr. 2007;10(8):855-61.

121. Leyna GH, Mmbaga EJ, Mnyika KS, Klepp KI. Validation of the Radimer/Cornell food insecurity measure in rural Kilimanjaro, Tanzania. Public Health Nutr. 2008;11(7):684-9.

122. Kendall A, Olson CM, Frongillo EA. Validation of the Radimer/ Cornell Measures of Hunger and Food Insecurity. J Nutr. 1995; 125(11):2793-801.

123. Hamelin AM, Habicht JP, Beaudry M. Food insecurity: consequences for the household and broader social implications. J Nutr. 1999;129(2S Suppl):525S-8S. 
124. Albert PL, Sanjur D. The adaptation and validation of the food security scale in a community of Caracas, Venezuela. Arch Latinoam Nutr. 2000;50(4):334-40.

125. Maxwell DAC, Levin C, Armar-Klemesu M, Zakariah S, Lamptey GM. Alternative food security indicators: revisiting the frequency and severity of 'coping strategies'. Food Policy. 1999;24:411-29.

126. Maxwell DG. Measuring food insecurity: the frequency and severity of 'coping strategies'. Food Policy. 1996;21(3): 291-303.

127. Maxwell D. Measuring food insecurity: can an indicator based on localized coping behaviors be used to compare across contexts? Food Policy. 2008;33:533-40.

128. Kennedy G, Berardo A, Papavero C, Horjus P, Ballard T, Dop M, et al. Proxy measures of household food consumption for food security assessment and surveillance: comparison of the household dietary diversity and food consumption scores. Public Health Nutr. 2010;13(12):2010-8.

129. FAO. Guidelines for measuring household and individual dietary diversity. Rome: FAO; 2010.

130. Arimond M, Wiesmann D, Becquey E, Carriquiry A, Daniels M, Deitchler M, Fanou-Fogny N, Joseph M, Kennedy G, MartinPrevel Y, Torheim LE. Simple food group diversity indicators predict micronutrient adequacy of women's diets in 5 diverse, resource-poor settings. J Nutr. 2010;140(11):2059S-69S.

131. Martin-Prevel Y, Becquey E, Arimond M. Food group diversity indicators derived from qualitative list-based questionnaire misreported some foods compared to same indicators derived from quantitative 24-hour recall in urban Burkina Faso. J Nutr. 2010;140(11):2086S-93S. 